\title{
PENGARUH PEMBELAJARAN BERBASIS MASALAH TERHADAP PEMAHAMAN SISWA MENGENAI HAK DAN KEWAJIBAN SISWA SEKOLAH DASAR SEBAGAI WARGA NEGARA
}

\author{
Hendra Prasetia ${ }^{1}$, Muhari ${ }^{2}$, Waspodo Tjipto Subroto ${ }^{3}$ \\ ${ }^{1}$ Mahasiswa Program Pascasarjana, Prodi Pendidikan Dasar, Universitas Negeri Surabaya, \\ ${ }^{2 \& 3}$ Dosen Pascasarjana, Prodi Pendidikan Dasar, Universitas Negeri Surabaya \\ e-mail: hendraprass86@gmail.com
}

\section{Received : Maret 2019}

Reviewed : April 2019

Accepted : $\quad$ Mei 2019

Published : Mei 2019

ABSTRACT

This study aimed to research the effect of problem based learning on students' understanding of the rights and obligations of primary school students as citizenship. The type of the research was experimental research with pretest-posttest control group research design. Results of testing the hypothesis that $t$ value obtained is equal to 5.216 and a significance value of 0.000. Thus the $t$ value obtained is greater than t table (5.216> 2.408), while the significance value is smaller than the value of a $(0.000<0.05)$. Based on these results, the hypothesis is accepted, meaning that a significant difference between problem-based learning, the students' understanding of the rights and obligations of primary school students as citizenship.

Keywords: Problem Based Learning, Students Understanding, the Rights and Duties of Students.

\section{ABSTRAK}

Penelitian ini bertujuan untuk mengetahui pengaruh model Pembelajaran berbasis masalah terhadap pemahaman siswa mengenai hak dan kewajiban siswa sekolah dasar sebagai warga negara. Jenis penelitian yang dilakukan adalah penelitian eksperimen dengan bentuk desain penelitian pretest-posttest control group design. Hasil pengujian hipotesis menjelaskan nilai $t$ hitung yang didapat yaitu sebesar 5.216 dan nilai signifikansi sebesar 0,000, hasil pengujian hipotesis tersebut menunjukkan bahwa nilai $t$ hitung yang didapat lebih besar dari nilai $t$ dalam tabel $(5,216>2,408)$ sedangkan nilai signifikansi tersebut lebih kecil dari nilai $\alpha$ $(0,000<0,05)$. Berdasarkan hasil tersebut, maka hipotesis diterima, artinya terdapat pengaruh yang signifikan antara pembelajaran berbasis masalah, terhadap pemahaman siswa akan hak dan kewajiban siswa sekolah dasar sebagai warga negara.

Kata Kunci : Pembelajaran Berdasarkan Masalah, Pemahaman Siswa, Hak dan kewajiban siswa.

\section{PENDAHULUAN}

Dalam meningkatan kualitas sumber daya manusia dalam sebuah bangsa juga tidak dapat dipisahkan dengan pendidikan. Hal ini tidak dapat diabaikan karena pendidikan adalah dasar atau fundamen dari masyarakat yang berkualitas (Tilaar, 2001:3). Upaya meningkatkan sumber daya manusia tidak dapat dilakukan dengan hanya memberikan kesempatan memperoleh pendidikan, akan tetapi harus disertai dengan peningkatan mutu pendidikan itu sendiri.
Pendidikan merupakan salah satu faktor yang menentukan maju mundurnya sumber daya manusia. Pendidikan dapat dimaknai sebagai proses mengubah tingkah laku anak didik agar menjadi manusia dewasa yang mampu hidup mandiri dan sebagai anggota masyarakat dalam lingkungan alam sekitar dimana individu itu berada. Pendidikan tidak hanya mencakup pengembangan intelektualitas saja, akan tetapi lebih ditekankan pada proses pembinaan kepribadian anak didik secara menyeluruh sehingga anak menjadi lebih dewasa (Sagala, 2009: 3). 
Kegiatan pembelajaran juga ikut memberikan kontribusi terhadap mutu pendidikan. Model-model pembelajaran yang hendak diterapkan oleh guru menjadi bahan kajian penting dalam pendidikan. Pelaksanaan pembelajaran yang fungsional dan efektif merupakan salah satu aspek dalam upaya meningkatkan mutu pendidikan. Dalam pelaksanaan tersebut, terjadi interaksi antara guru dalam keberadaannya untuk mengajar dan siswa dalam keberadaannya untuk belajar. Mengajar dalam hal ini, tentulah dengan menggunakan metode tertentu sebagai salah satu komponen dalam mencapai tujuan pembelajaran, yang dalam pelaksanaannya tidaklah terlepas dari jenis pendekatan yang dilaksanakan. Oleh karena itu peranan yang sangat menentukan dari penggunaan suatu metode pengajaran yang disertai jenis pendekatan tertentu, memerlukan metode pengajaran yang serasi dan jenis pendekatan yang tepat.

Model pembelajaran dapat dipahami sebagai pendekatan yang luas dan menyeluruh serta dapat diklasifikasikan berdasarkan tujuan pembelajarannya, sintaks (pola urutannya), dan sifat lingkungan belajarnya (Trianto, 2009). Model pembelajaran adalah kerangka konseptual yang melukiskan prosedur sistematik dalam mengorganisasikan pengalaman belajar untuk mencapai tujuan pembelajaran tertentu dan berfungsi sebagi pedoman bagi perancang pembelajaran dan para guru dalam merancang dan melaksanakan proses belajar mengajar. Model pembelajaran yang baik digunakan sebagai acuan perencanaan dalam pembelajaran di kelas ataupun tutorial untuk menentukan perangkat-perangkat pembelajaran yang sesuai dengan bahan ajar yang diajarkan.

Pemilihan model pembelajaran yang sesuai dengan tujuan kurikulum dan potensi siswa merupakan kemampuan dan keterampilan dasar yang harus dimiliki oleh seorang guru. Karena model dan metode pembelajaran yang digunakan oleh guru berpengaruh terhadap kualitas proses belajar mengajar yang dilakukannya. Kondisi proses belajar mengajar di lingkungan sekolah dewasa ini masih diwarnai oleh penekanan pada aspek pengetahuan dan masih sedikit yang mengacu pada pelibatan siswa dalam proses belajar itu sendiri.

Hal ini akan berpengaruh secara langsung terhadap kemampuan dan pemahaman siswa dalam belajar. Melihat permasalahan tersebut, maka isu yang sering diangkat oleh media masa cetak maupun elektronik tentang rendahnya mutu pendidikan kita dewasa ini secara kualitatif diduga disebabkan karena model pembelajaran yang dianut oleh guru didasarkan atas asumsi tersembunyi salahsatunya bahwa Pendidikan adalah suatu pengetahuan yang bisa dipindahkan secara utuh dari pikiran guru ke pikiran siswa (Sagala, 2009).

Model pembelajaran yang berpusat pada siswa dan penciptaan suasana yang menyenangkan sangat diperlukan untuk meningkatkan hasil belajar siswa dalam mata pelajaran PPKn. Dalam hal ini penulis memilih pengaruh pembelajaran berbasis masalah terhadap pemahaman siswa mengenai hak dan kewajiban siswa sekolah dasar sebagai warga masyarakat. Pembelajaran berbasis masalah adalah suatu model pembelajaran yang menggunakan masalah sebagai titik awal untuk mengakuisisi pengetahuan baru. Siswa belajar menggunakan masalah autentik tertentu untuk belajar konten (isi) pelajaran dan sebaliknya siswa juga belajar keterampilan khusus untuk menyelesaikan masalah dengan menggunakan sarana berupa isi/konten pelajaran (Ibrahim, 2012:8).

Beberapa hasil penelitian yang dikutip oleh Yazdani (2002) menunjukkan keberhasilan pembelajaran berbasis masalah. Satu penelitian menunjukkan bahwa siswa PBM menghasilkan penjelasan-penjelasan yang lebih rinci, menggunakan kalimat mereka sendiri, dan lebih baik dalam pengintegrasian pengetahuan baru, namun mereka kurang akurat dibandingkan siswa-siswa tradisional, yang berkinerja lebih baik pada pengenalan pola. Model pembelajaran berbasis masalah terbukti dapat meningkatkan berfikir siswa (Eldy, 2013:3). Sejalan dengan yang dikemukakan Eldy, Penelitian lain menemukan bahwa siswa PBM menghasilkan penjelasanpenjelasan yang lebih akurat, koheren, dan komprehensif daripada siswa-siswa non PBM (Nur, 2011:32).

Perencanaan pembelajaran berbasis masalah pada pembelajaran PPKn berfokus pada merancang permasahan yang autentik dan kolaborasi. Permasalahannya harus melibatkan peserta didik, membangkitkan minat, dan peserta didik tertarik pada permasalahan tersebut (Gallager, 2013:112). Sedangkan kolaborasi disini peserta didik bekerjasama dalam kelompok untuk melakukan penelitian, menerapkan logika, penalaran, dan menyusun solusi untuk masalah yang kompleks (English \& Kitsantas, 2013:131). Jadi dalam hal ini siswa diminta menyelesaikan masalah di dalam kelompoknya agar solusi dari permasalahan yang dihadapi mudah untuk dicari penyelesaiannya.

Salah satu materi pembelajaran dalam mata pelajaran PPKn di tingkat sekolah dasar yaitu materi tentang hak dan kewajiban siswa sebagai warga negara. Materi ini penting diajarkan, sebagai tempat partisipasi warga negara di dalam pembangunan nasional. Karena pembangunan nasional identik dengan membangun generasi muda. Siswa sebagai generasi muda penerus bangsa dan pemegang estafet dari bangsa dan negara ini, 
perlu dibangun wawasan dan pengetahuannya terhadap negeri ini akan hak dan kewajibannya sebagai warga negara. Oleh karena itu partisipasi warga negara perlu diajarkan dalam berbagai cara, seperti misalnya membayar pajak, memelihara kelestarian lingkungan, mengikuti program wajib belajar, tertib lalu lintas, mengadakan Siskamling, dan lain sebagainya.

Hak dan kewajiban merupakan suatu hal yang terikat satu sama lain, sehingga dalam praktiknya harus dijalankan dengan seimbang. Hak adalah kuasa untuk menerima atau melakukan sesuatu yang semestinya diterima atau dilakukan oleh pihak tertentu, dan tidak dapat oleh pihak lain manapun juga yang pada prinsipnya dapat dituntut paksa olehnya (Soemarsono, 2005:5).

Terkait dengan pokok bahasan hak dan kewajiban pada pembelajaran PPKn juga diajarkan pada jenjang kelas V SD yang akan dibahas dalam penelitian ini dianggap sangat sesuai disajikan menggunakan pembelajaran berbasis masalah, sebab sesuai dengan kehidupan seharihari. Penyampaian materi tidak hanya menggunakan buku PPKn, tetapi dikombinasikan dengan bahan dari sumber lainnya yang sesuai dengan materi yang diajarkan. Hal ini tentu akan mudah dipahami peserta didik dan menarik minat untuk mempelajarinya.

Berdasarkan uraian diatas diduga bahwa pembelajaran dengan menggunakan pembelajaran pada mata pelajaran PPKn tentang hak dan kewajiban siswa sebagai warga masyarakat dapat berpengaruh terhadap pemahaman siswa. Sebagai solusi, maka penelitian ini mencoba menggunakan pembelajaran berbasis masalah sebagai alternatif dalam mencari pengaruh pembelajaran berbasis masalah dengan pemahaman siswa akan hak dan kewajibannya sebagai warga negara.

Sehubungan dengan permasalahan tersebut, maka penelitian ini dirancang untuk mengkaji pengaruh pembelajaran berbasis masalah terhadap pemahaman siswa mengenai hak dan kewajiban siswa sekolah dasar sebagai warga negara.

\section{METODE}

Jenis Penelitian yang dilaksanakan adalah penelitian quasi eksperimen, dengan menggunakan pendekatan kuantitatif sehingga dihasilkan data berupa kuantitatif. Dalam penelitian eksperimen ini akan ada kelompok perlakuan dan ada kelompok kontrol. Kelompok kontrol akan diberi perlakuan dengan menggunakan pembelajaran konvensional seperti biasanya dilakukan yakni dengan ceramah dan mengerjakan lembar kerja siswa. Sedangkan kelompok perlakuan atau eksperimen akan diberi perlakuan dengan menggunakan pembelajaran berbasis masalah.

Tujuan dari penelitian eksperimen ini yaitu untuk meneliti hubungan sebab akibat antar variabel dengan manipulasi variabel bebas. Rancangan penelitian yang digunakan dalam penelitian ini adalah penelitian eksperimen dengan teknik pretest-posttest control group design. Rancangan penelitian ini dimulai dengan melakukan pretest sebagai uji awal untuk mengetahui konsepsi awal siswa, selanjutnya dikenakan perlakuan dalam jangka waktu tertentu, kemudian dilakukan posttest sebagai uji akhir (Sugiyono, 2012.).

Penelitian eksperimen dilakukan pada kedua kelompok diawali dengan pemberian tes awal (Pre-Test), kemudian kelas eksperimen diberi pembelajaran berbasis masalah sedangkan kelas kontrol dengan menggunakan pembelajaran seperti biasanya dilakukan yakni dengan ceramah. Setelah pemberian perlakuan selesai diadakan pengukuran kembali (post-test).

Lokasi penelitian ini adalah kelas VA dan VB SDI Nurul Huda, Kota Surabaya. Sekolah ini dipimpin oleh Drs. Abdul karim Latief. Secara khusus penelitian dilakukan di kelas V. Pemilihan tempat ini berdasarkan alasan bahwa peneliti mendapat masukan dari pengajar di SD tersebut, bahwa siswa kelas VA kurang pemahamannya akan hak dan kewajiban, diantaranya seperti siswa atau pelajar yang kurang begitu bersemangat dalam melakukan kegiatan-kegiatan belajar, siswa saat tidak ada guru di dalam kelas pun kurang punya kesadaran untuk mau belajar sendiri, seringnya siswa berbicara dan kurang perhatian terhadap penjelasan guru, siswa kurang konsentrasi dalam pembelajaran hal ini ditunjukkan dengan seringnya peserta didik ijin untuk ke kamar mandi.

Proses pengembangan instrumen ini peneliti menggunakan tes hasil belajar siswa sebagai teknik dalam pengumpulan data. Tes hasil belajar siswa digunakan untuk memperoleh data tentang pemahaman siswa mengenai hak dan kewajiban siswa sebagai warga pada ranah kognitif dilakukan dengan memberikan tes tertulis yang diberikan sebelum pembelajaran (Pretest) dan sesudah pembelajaran (post test).

\section{HASIL DAN PEMBAHASAN}

\section{Profil SD Islam Nurul Huda Surabaya}

Sekolah Dasar Islam atau yang dikenal SDI Nurul Huda Surabaya yang berlokasi di alamat: Jl. Gayungan PTT No.49 Surabaya didirikan pada tanggal 17 Maret 1969 dengan nomer statistik sekolah (NSS) 104351907015 dan NPSN: 20533102 
SDI Nurul Huda Surabaya mempunyai visi: "Menyiapkan Generasi-Generasi yang berkepribadian qur'ani, bertaqwa, cerdas, kreatif, bertanggung jawab, cinta rasulullah saw dan "ulama”.

Sedangkan Misi dari SDI Nurul Huda Surabaya adalah:

1. Menyelenggarakan pendidikan berbudaya pesantren yang berpaham Ahlussunah wal jama'ah.

2. Mencintai Al-Qur'an dan mengamalkan ajaran agama Islam dalam kehidupan sehari-hari.

3. Menumbuhkan penalaran yang baik, siswa mau belajar, rasa ingin tahu, senang membaca, memiliki inovasi dan kreatif serta bertanggung jawab.

4. Mengenal memahami sejarah hidup Rasulullah SAW, para sahabat, danUlama'salafus shalih sebagai teladan dalam pergaulan sehari-hari.

Dalam perkembangannya, bahwa jumlah murid dari tahun pelajaran 2012/2013 sampai dengan tahun pelajaran 2015/2016 seperti tersaji dalam table 1 berikut ini:

Tabel 1 Data perkembangan murid SDI Nurul Huda

Surabaya Tahun Pelajaran 2013/2014-2015/2016

\begin{tabular}{ccccc}
\hline Kelas & Rombel & $\begin{array}{c}\text { Tahun } \\
\text { Pelajaran } \\
\text { 2013/2014 }\end{array}$ & $\begin{array}{c}\text { Tahun } \\
\text { Pelajaran } \\
\mathbf{2 0 1 4 / 2 0 1 5}\end{array}$ & $\begin{array}{c}\text { Tahun } \\
\text { Pelajaran } \\
\mathbf{2 0 1 5 / 2 0 1 6}\end{array}$ \\
\hline Kelas 1 & 2 & 53 & 50 & 54 \\
Kelas 2 & 2 & 64 & 53 & 50 \\
Kelas 3 & 2 & 49 & 55 & 53 \\
Kelas 4 & 2 & 53 & 49 & 55 \\
Kelas 5 & 2 & 51 & 53 & 49 \\
Kelas 6 & 2 & 57 & 51 & 53 \\
\hline Jumlah & 12 & 327 & 311 & 314 \\
\hline
\end{tabular}

Sumber: Monografi Sekolah Tahun Pelajaran 2015/2016

Berdasarkan data dalam tabel di atas dapat diketahui bahwa masing-masing kelas memiliki 2 rombongan belajar dengan jumlah siswa pada tahun pelajaran 2013-2014 sebanyak 327 siswa dan pada tahun pelajaran 2014/2015 sebanyak 311 siswa dan pada tahun pelajaran 2015/2016 mengalami peningkatan dengan jumlah 314 siswa.

Sarana dan prasarana adalah segala kelangkapan yang dimiliki sekolah yang digunakan untuk mendukung pelaksanaan belajar mengajar dikelas maupun pelaksanaan administrasi pendidikan di sekolah. Dalam upaya mendukung pelaksanaan program pendidikan dan pengajaran di sekolah, maka beberapa sarana yang dimiliki SDI Nurul Huda Surabaya, diantaranya seperti:
Tabel 3 Data sarana dan Prasarana Pendidikan SDI Nurul Huda Surabaya

\begin{tabular}{lllc}
\hline No. & Jenis Sarpras & Jumlah & Ket \\
$\mathbf{1}$ & Lemari & 12 unit & Baik \\
$\mathbf{2}$ & Kursi & 250 unit & Baik \\
\hline No. & Jenis Sarpras & Jumlah & Ket \\
$\mathbf{3}$ & Rak buku & 6 unit & Baik \\
$\mathbf{4}$ & Papan Tulis & 12 unit & Baik \\
$\mathbf{5}$ & Rak Perpus & 4 unit & Baik \\
$\mathbf{6}$ & Mesin Tik & 2 unit & Baik \\
$\mathbf{7}$ & Komputer & 6 unit & Baik \\
$\mathbf{8}$ & Bola Sepak & 3 unit & Baik \\
$\mathbf{9}$ & Alat IPA & 10 unit & Baik \\
$\mathbf{1 0}$ & Kerangka Manusia & 2 unit & Baik \\
$\mathbf{1 1}$ & Alat IPS & 10 unit & Baik \\
$\mathbf{1 2}$ & Globe & 2 unit & Baik \\
\hline
\end{tabular}

Sumber: Buku profil sekolah Tahun 2015/2016

Data dalam tabel di atas menunjukkan bahwa sarana dan prasarana yang dimiliki secara keseluruhan dalam kondisi baik. Adapun data sumber daya manusia yang ada di SDI Nurul Huda Surabaya dapat disajikan dalam tabel berikut ini:

Tabel 2 Data Sumber Daya Manusia SDI Nurul Huda

\begin{tabular}{clc}
\multicolumn{3}{c}{ Surabaya } \\
\hline No. & Data Guru dan Staf & Jumlah \\
\hline 1 & Kepala Sekolah & 1 \\
2 & Guru Kelas & 12 \\
3 & Guru Penjaskes & 2 \\
4 & Guru Agama & 2 \\
5 & Guru Bahasa Inggris & 2 \\
6 & Guru Bahasa Arab & 1 \\
7 & TU & 2 \\
8 & Penjaga & 2 \\
\hline Jumlah & 24 \\
\hline
\end{tabular}

Sumber: Buku profil sekolah Tahun 2015/2016

Adapun data guru berdasarkan jenis kelamin dan jenjang pendidikan dapat peneliti sajikan dalam tabel berikut ini:

Tabel 4 Data Sumber Daya Manusia SDI Nurul Huda

\begin{tabular}{|c|c|c|c|c|}
\hline \multirow{4}{*}{ No. } & \multicolumn{4}{|c|}{ Surabaya } \\
\hline & \multirow{3}{*}{$\begin{array}{c}\text { Jenjang } \\
\text { Pendidikan }\end{array}$} & \multirow{2}{*}{\multicolumn{2}{|c|}{$\begin{array}{c}\text { Jenis } \\
\text { kelamin }\end{array}$}} & \multirow[t]{3}{*}{ Jumlah } \\
\hline & & & & \\
\hline & & $\mathrm{L}$ & $\mathrm{P}$ & \\
\hline 1 & SMP & 2 & - & 2 \\
\hline 2 & SMA/SPG & 1 & - & 1 \\
\hline 3 & D2 & 1 & 3 & 4 \\
\hline 4 & D3 & 1 & - & 1 \\
\hline 5 & Sarjana (S1) & 7 & 9 & 15 \\
\hline \multicolumn{2}{|c|}{ Jumlah } & 12 & 12 & 24 \\
\hline
\end{tabular}

Sumber: Buku profil sekolah Tahun 2015/2016

Berdasar data dalam tabel diatas guru di SDI Nurul Huda Surabaya adalah guru perempuan dan jenjang pendidikan guru terbanyak adalah sarjana (S1). Sedangkan 
data sumber daya manusia berdasarkan usia dapat disajikan dalam tabel berikut ini:

Tabel 5 Data Sumber Daya Manusia SDI Nurul Huda

\begin{tabular}{lcc}
\multicolumn{3}{c}{ Surabaya } \\
\hline No. & Usia & Jumlah \\
\hline 1 & $<30$ Thun & 5 \\
2 & $31-35$ & 4 \\
3 & $36-40$ & 5 \\
4 & $41-45$ & 6 \\
5 & $>46$ Tahun & 4 \\
\hline Jumlah & & 24 \\
\hline
\end{tabular}

Sumber: profil sekolah Tahun 2015/2016

\section{Struktur Organisasi SDI Nurul Huda Surabaya}

Susunan organisasi SDI Nurul Huda Surabaya merupakan sistem dari keseluruhan program kegiatan dalam rangka penyelenggaraan sekolah untuk mencapai tujuan pendidikan pada sekolah. Dalam melaksanakan program tersebut kepala sekolah dalam bidang kurikulum, sarana prasarana, kesiswaan, humas dan kaur tata usaha yang membidangi pendidikan dan pengajaran, kepegawaian, keuangan, umum, perpustakaan, serta piket. Kemudian dewan guru, wali kelas, guru piket yang secara langsung berhadapan dengan siswa/siswi.

1. Deskripsi Model Pembelajaran berdasarkan Masalah (X) kelas Eksperimen dan kelas Kontrol

Untuk mengetahui baik tidaknya kondisi variabel penelitian. Dengan didasarkan pada nilai rata-rata mean yang kemudian dilakukan standarisasi pengkategorian dengan mengacu pada indikator rentang pengukuran nilai yang dikemukakan Arikunto, (2009:23), apabila nilai rata-rata berada pada rentang nilai:

$$
\begin{gathered}
\text { Interval kelas }=\frac{\text { Nilaitertinggi- Nilaiterendah }}{\text { Jumlah Kelas }}=\frac{5-1}{5} \\
=0,8
\end{gathered}
$$

Tabel 6 Kategori skala Interval

\begin{tabular}{cc}
\hline Skala & Kategori \\
\hline$<20 \%$ & Tidak baik \\
$20-40 \%$ & Kurang baik \\
$41-60 \%$ & Cukup baik \\
$61-80 \%$ & Baik \\
\hline $81-100 \%$ & Sangat baik \\
\hline & (Arikunto, 2009:23)
\end{tabular}

2. Deskripsi Pretest dan Postest pemahaman Hak dan kewajiban sebagai warga masyarakat (Y) kelas Kontrol dan kelas Eksperimen a. Deskripsi Pre Test dan Post Test pemahaman hak dan kewajiban siswa sebagai warga negara (Y) Kelas Kontrol

Nilai Pre Test belajar siswa kelas kontrol merupakan pencapaian nilai yang dicapai kelas kontrol sebelum diterapkan model pembelajaran konvensional, berdasarkan hasil nilai Pre Test yang dicapai siswa diketahui bahwa nilai Pre Test untuk siswa kelas kontrol dengan rata-rata nilai yaitu 67,2.

Selanjutnya adalah pencapaian nilai Post Test kelas Kontrol setelah diberikan pembelajaran konvensional, secara jelas seperti tersaji dalam tabel berikut ini:

\begin{tabular}{|c|c|c|}
\hline NO. & NAMA SISWA & NILAI \\
\hline 1 & ADIY AL ANSORI & 81 \\
\hline \multirow[t]{2}{*}{2} & AHMAD ABDUH & 65 \\
\hline & SACHIYUDDIN & \\
\hline \multirow[t]{2}{*}{3} & ALIFIA NOVIORA JUNI LIA & 78 \\
\hline & WATI & \\
\hline 4 & ALTHAF MUCHARI HELMI & 75 \\
\hline 5 & AYU SYA' DYAH & 69 \\
\hline 6 & BALQISTA AYUSANI & 73 \\
\hline 7 & FARAH FIRDAUSI NI'MAH & 76 \\
\hline 8 & FIRDA SHOFIRO & 75 \\
\hline 9 & IKA AULIA NUR LAYLY & 57 \\
\hline 10 & INAYAH KHOIRUNNISA & 66 \\
\hline \multirow[t]{2}{*}{11} & LAILA DWI SENJA & 55 \\
\hline & RAHMADHANI & \\
\hline 12 & LAILI MUTI'ATUL KHOIROH & 63 \\
\hline 13 & M. HANIF ALVIANUDDIN & 58 \\
\hline \multirow[t]{2}{*}{14} & MUHAMMAD DIDI EKA & 68 \\
\hline & DIYANTU & \\
\hline \multirow[t]{2}{*}{15} & MUHAMMAD GILANG & 75 \\
\hline & RHAMADAN & \\
\hline 16 & NUR AFIFATUL AF'IDAH & 48 \\
\hline 17 & PINGKAN AGUM SASIKIRANA & 50 \\
\hline 18 & RAHMA NURIIL PAHLEFI & 46 \\
\hline 19 & RIZKI ABDILLAH & 77 \\
\hline 20 & SALSABILA RACHMAN & 76 \\
\hline 21 & TIARA HARINDA MAWADDAH & 77 \\
\hline 22 & VINA SOBACHUL FITRIYAH & 48 \\
\hline \multirow[t]{3}{*}{23} & ZAHRA NATASYA INDRA & 56 \\
\hline & JUMLAH & 1512 \\
\hline & RATA-RATA NILAI & 65,7 \\
\hline
\end{tabular}

Tabel 6 Pencapaian Nilai Post Test Siswa Kelas Kontrol

Berdasarkan data dalam tabel diatas, diketahui bahwa nilai Post Test rata-rata nilai yang dicapai siswa kelas kontrol yaitu 65,7. 
b. Deskripsi Pre Test dan Post Test pemahaman hak dan kewajiban siswa sebagai warga masyarakat (Y) Kelas Eksperimen

Nilai Pre test pemahaman siswa akan hak dan kewajibannya sebagai warga masyarakat kelas eksperimen merupakan pencapaian nilai yang dicapai kelas eksperimen sebelum diterapkan model pembelajaran berbasis masalah, berdasarkan hasil nilai Pre test yang dicapai siswa, diketahui bahwa nilai Pre Test sebelum model pembelajaran berbasis masalah dengan rata-rata nilai pre test yang dicapai siswa kelas eksperimen yaitu 68,42.

Setelah menggunkan model pembelajaran berbasis masalah kelas eksperimen, secara jelas tersaji dalam tabel berikut ini:

Tabel 7 Pencapaian Nilai Post Test Siswa Kelas Eksperimen

\begin{tabular}{llc}
\hline NO. & NAMA SISWA & NILAI \\
\hline 1 & AHMAD ARDYANSYAH & 85 \\
2 & ALICIA FEBRY & 80 \\
3 & ALIVIA MUMTAZA & 85 \\
4 & AURELIA AMARTA & 86 \\
5 & FITRIA NITA & 78 \\
6 & JENI RANI & 76 \\
7 & MUHAMMAD ADITYA & 82 \\
8 & M. DHIYA'UL HAQ & 80 \\
9 & M. DHIFA ARYA & 75 \\
10 & MUHAMMAD IQBAL & 81 \\
11 & M. PUTRA KARIM & 83 \\
12 & M. RAFIAN & 79 \\
13 & M. ZAINAL ABIDIN & 78 \\
14 & NUR ASYHA FAUZIAH & 89 \\
15 & NURIL FIRDAUS & 82 \\
16 & OKTY AGUSTIANA & 75 \\
17 & M. PUTRA KARIM & 79 \\
18 & M. RAFIAN & 69 \\
19 & M. ZAINAL ABIDIN & 56 \\
20 & PUTRI SALMA & 77 \\
21 & RACHMADI RIZKY & 78 \\
22 & RIKI OKTARINGGA & 80 \\
23 & SASHA SANTIKA & 81 \\
24 & SEPTIAN RIZKY & 82 \\
25 & TRIONO ARIE & 79 \\
26 & WILLY NUR & 81 \\
& $\quad$ JUMLAH & 79,19 \\
\hline & RATA-RATA NILAI & \\
\hline & & \\
\hline
\end{tabular}

Sumber: diolah Juni 2016

Berdasarkan data dalam tabel diatas, diketahui bahwa nilai Post Test setelah model pembelajaran berbasis masalah dengan rata-rata nilai post test yang dicapai siswa kelas eksperimen yaitu 79,19.
Berdasarkan data yang terdapat dalam tabel diperoleh data sebagai berikut:

Tabel 8 Perubahan Post Test Hasil Belajar Siswa

\begin{tabular}{cc}
\hline Kelas & Rata-rata nilai Post Test \\
\hline Kelas Kontrol & $\mathbf{6 5 , 7}$ \\
Kelas Eksperimen & $\mathbf{7 9 , 1 9}$ \\
\hline & Sumber: diolah Juni 2016
\end{tabular}

Sedangkan analisis data terhadap hasil post test yang dilakukan terhadap kelas control dan kelas eksperimen, maka diperoleh suatu hasil seperti tersaji dalam tabel berikut ini:

Tabel 9 Uji Kesamaan Post Test dua rata-rata kelas control dan kelas ekperimen

Group Statistics

\begin{tabular}{rlcccc}
\hline \multirow{2}{*}{ Kelas } & N & Mean & $\begin{array}{c}\text { Std. } \\
\text { Deviation }\end{array}$ & $\begin{array}{c}\text { Std. } \\
\text { Error } \\
\text { Mean }\end{array}$ \\
& & & & & \\
\multirow{2}{*}{ Nilai } & Eksperimen & 26 & 79.08 & 6.183 & 1.213 \\
& Kontrol & 23 & 65.74 & 11.270 & 2.350 \\
\hline
\end{tabular}

Sumber: diolah Juni 2016

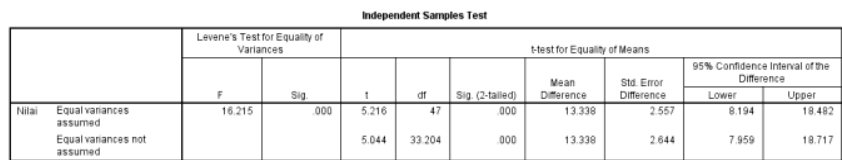

Sumber: diolah Juni 2016

1) Untuk nilai posttest pada kelas kontrol sebesar 65,7 kelas eksperimen 79,19. Simpangan baku/standart deviasi kelas control 11,270 kelas eksperimen 6,183.

2) Pada table terllihat $T$ hitung sebesar 5,216 dengan derajat kebebasan (df) 47 diperoleh angka signifikasi (sig. 2 tailed) sebesar 0,000 .

3) Merumuskan hipotesis uji indpedent sampel tes uji pretes

a. $H_{0}=$ tidak ada perbedaan antara pretes kelas control dengan pretes kelas eksperimen.

b. $H_{a}=$ ada perbedaan antara pretes kelas control dengan pretes kelas eksperimen.

4) Menentukan T Hitung dan Signifikasi

Dari table output di atas diketahui $\mathrm{T}$ hitung adalah 5,216 dan signifikasi sebesar 0,000.

5) Menentukan $T$ table yang diperoleh dari table signifikasi 0,05:2 $=0,025$ (uji dua sisi) dengan derajat $(\mathrm{df})=\mathrm{n}-2$ atau 49-2 = 47 adalah sebesar 2,408.

6) Kaidah keputusan

a. Jika t hitung $<$ t table maka $H_{0}$ diterima.

b. Jika t hitung $>\mathrm{t}$ table maka $H_{0}$ ditolak.

c. Jika signifikasi $>0,05$ maka $H_{0}$ diterima.

d. Jika Signifikasi $<0,05$ maka $H_{0}$ ditolak. 
7) Membuat kesimpulan.

Karena nilai $\mathrm{t}$ hitung $>\mathrm{t}$ table $(5,216>2,408)$ dan nilai signifikasi $(0,000<0,05)$ maka $H_{0}$ ditolak. Dengan demikian dapat disimpulkan bahwa ada perbedaan pada pemahaman siswa postest kelas control dan kelas eksperimen. Dengan kata lain dapat diketahui bahwa dari postest yang diberikan diketahui bahwa pemahaman awal pada kelas control dan kelas eksperimen adalah berbeda.

Berdasarkan hasil pengujian hipotesis diperoleh hasil T-hitung sebesar 5,216 dan nilai signifikansi sebesar 0,000. Dengan demikian nilai t hitung yang didapat lebih besar dari nilai $\mathrm{T}$ dalam tabel $(5,216>2,408)$ sedangkan nilai signifikansi tersebut lebih kecil dari nilai $\alpha(0,000<0,05)$. Berdasar hasil tersebut maka hipotesis ditolak, artinya terdapat pengaruh yang signifikan antara pembelajaran berbasis masalah $(\mathrm{X})$, terhadap pemahaman siswa akan Hak dan kewajiban siswa sekolah dasar (Y) sebagai warga masyarakat.

\section{PENUTUP}

\section{Simpulan}

Berdasarkan hasil penelitian dan analisis yang dilakukan, maka dapat dikemukakan simpulan sebagai berikut:

Ada pengaruh model pembelajaran berbasis masalah terhadap pemahaman siswa terhadap hak dan kewajibannya sebagai warga negara. Hal ini dibuktikan dengan adanya perbedaan yang signifikan antara siswa yang mendapat perlakuan dengan kegiatan pembelajaran berbasis masalah terhadap pemahaman siswa terhadap hak dan kewajibannya sebagai warga negara. Berdasarkan hasil analisis pengujian hipotesis diperoleh hasil t hitung sebesar 5,216 dan nilai signifikansi sebesar 0,000. Dengan demikian nilai $\mathrm{t}$ hitung yang didapat lebih besar dari nilai $\mathrm{t}$ dalam tabel $(5,216>2,408)$ sedangkan nilai signifikansi tersebut lebih kecil dari nilai $\alpha(0,000<0,05)$.

Berdasarkan hasil tersebut, maka hipotesis ditolak, artinya terdapat pengaruh yang signifikan antara pembelajaran berbasis masalah, terhadap pemahaman tentang hak dan kewajiban siswa sekolah dasar sebagai warga negara.

\section{Saran}

Terkait dengan hasil penelitian ini, maka beberapa saran yang perlu peneliti sampaikan adalah model pembelajaran berbasis masalah perlu diimplementasikan di dalam kelas karena dapat meningkatkan pemahaman siswa terhadap pembelajaran. Pembelajaran sebaiknya dirancang sesuai kebutuhan dan kemampuan individu siswa. Agar pembelajaran menarik guru dapat menggunakan media yang dapat menarik perhatian siswa dan dapat meningkatkan kemampuan pemahaman siswa sehingga tujuan dari pembelajaran dapat tercapai. model pembelajaran berbasis masalah perlu diimplementasikan di dalam kelas karena dapat meningkatkan pemahaman siswa terhadap pembelajaran.

Hasil dari kajian empirik (penelitian) tentang pengaruh pembelajaran berbasis masalah terhadap pemahaman siswa akan hak dan kewajiban siswa sebagai warga negara, terbatas pada ranah kognitif saja sehingga perlu diadakan penelitian lanjutan untuk kompetensi yang berbeda dalam perbandingan yang sama agar dapat diketahui pula ranah afektif dan ranah psikomotorik siswa.

Bagi peneliti lain, yang akan meneliti hal yang terkait dengan penelitian ini dapat menggunakan variabelvariabel yang lainnya agar lebih bervariatif.

\section{DAFTAR PUSTAKA}

Amir T. (2010). Inovasi Pendidikan melalui Problem Based Learning. Jakarta: Kencana.

Anderson, P. (1972). Language Skills In Elementary Education. New York: Macmillan Publishing Co, Inc.

Anggriani, F. (2014). "Penerapan Metode Pembelajaran Berbasis Masalah Untuk Meningkatkan Hasil Belajar Siswa Pada Mata Pelajaran IPS Kelas IV SD Inpres 1 Margapura". Jurnal Kreatif Tadulako. Vol.4, No.5. hal 22-23.

Arends, R.I. (1997). Classroom Instruction and Management. New York: The Mc Graw-Hill Company.

Arifin, M. (1994). Pengembangan Strategi dan ModelModel Pembelajaran. Surabaya: Airlangga University Press.

Arikunto, S. (2006). Prosedur Penelitian: Suatu Pendekatan Praktik. Jakarta: Rineka Cipta.

Badan Penelitian dan Pengembangan HAM. (2012). "Pendidikan Berbasis Hak Asasi Manusia dan Pengembangan Rintisan Sekolah Bertaraf Internasional". Jurnal HAM. Vol.3 2012, hal55-73.

Budiharjo. 2002. Pembinaan dan Pengembangan Kurikulum. Jakarta: Bumi Aksara.

Contreras, P. (2012). "National Discretion and International Deference in the Restriction of Human Rights: A Comparison Between the Jurisprudence of the European and the Inter- 
American Court of Human Rights". Northwestern Journal of International Human Rights. Vol. 11, artikel 2, 2012. pp. 7-8.

Depdiknas. (2013). Standar Kompetensi Kurikulum Pendidikan Kewarganegaraan tahun 2013, Jakarta: Depdiknas.

Dimyati \& Mudjiono. (2006). Belajar dan Pembelajaran. Jakarta: Rineka Cipta.

Djamarah, S.B. dan Zain, A. (1996). Strategi Belajar Mengajar. Jakarta: Rineka Cipta.

Eldy, E.F. and Sulaiman, F. (2013). The Role of PBL in Improving Physicc Students' Creative Thinking and Its Imprint on Gender. Education and Research. Vol.1 No.6 Juni 2013. Hlm. 110 .

English, M. C. and Kitsantas, A. 2013. Supporting Student Self-Regulated Learning in problem \& based learning. Interdisciplinary Journal of Problembased Learning. Vol.7 No.2 Mei 2013. Hlm.128-150.

Fogarty, R. (1997). Problem based learning and other curriculum models for the multiple intelligences classroom. Arlington Heights, Illinois: Sky Light.

Gallagher, S.A. and Gallagher, J.J. (2013). Using Problembased Learning to Explore Unseen Academic Potential. Interdisiplinary Journal of Problembased Learning. Vol.7 No.1 Maret 2013. Pp. 111-131.

Grounlund, N.E. (1982). How To Write and Use Instructional Objectives. New York: Englewood Clift, Prentice Hall.

Ghullam H. dan Friska R. (2015). Pengembangan LKS Pembelajaran Berbasis Masalah Tema Bermain dengan Benda-benda Sekitar. Internasional Proceeding 6 Pedagogy International Seminar 2015. Bandung: UPI Bandung.

Hudoyo, H. (2002). Representasi Belajar Berbasis Masalah. Jurnal matematika atau pembelajarannya. Tahun VIII, Edisi khusus Juli 2002. Malang: Universitas Negeri Malang.

Ibrahim, M. (2012). Pembelajaran Berdasarkan Masalah. Surabaya: Unesa University Press.

IJCRR. (2002). "Rights Based Programming". International Journal of Child Rights and Research.Vol.2, 2002. pp.12-13.

Indonesia. (2002) UUD 1945 Setelah Amandemen Keempat Tahun 2002. Bandung: Pustaka Setia.
Kaelan. (2007). Pendidikan Kewarganegaraan. Yogyakarta: Paradigma.

Kemp, JE. (1994). Designing Effective Instruction. New York: Merril an Imprint of Macmillan College Publishing Company.

Mulyasa. (2003). Manajemen Berbasis Sekolah. Bandung; Remaja Rosdakarya.

Nasution, S. (2005). Berbagai Pendekatan dalam Proses Belajar dan Mengajar. Jakarta: Bumi Aksara.

Nur, M. Wikandari, P.R., dan Sugiarto, B. (2004). Teoriteori Pembelajaran Kognitif. Surabaya: PSMS Universitas Negeri Surabaya.

Nur, M. (2011). Model Pembelajaran Berdasarkan Masalah. Surabaya: Pusat Sains dan Matematika Sekolah UNESA.

Peraturan Menteri Pendidikan Nasional No. 22 tahun 2006 tentang Standar Isi.

Purcell, M. (2003). "Citizenship and the right to the Global City:Reimagning the Capitalist World Order". International Journal of Urban and Regional Research. Vol 27. September 2003. pp.3-4.

Poesprodjo (1987). Pendidikan dengan Cerdas. Jakarta: Pustaka Populer Obor.

Prasodjo, W. H. (2005). "Konstitusionalisme dan Hak Asasi Manusia". Jurnal ilmu Hukum Yuridika. Vol.20. 2015. hal.4-5.

Republik Indonesia, Undang-undang No.20 tahun 2003 tentang Sistem Pendidikan Nasional.

Rusman. (2010). Model-Model Pembelajaran. Jakarta: Rajawali Pers.

Sagala, S. (2009). Konsep dan Makna Pembelajaran. Bandung: Alfabeta.

Sardiman. 2000. Interaksi dan Motivasi Belajar Mengajar. Jakarta: Grafindo Persada.

Semiawan, C.R. (1991). Strategi Pembelajaran yang Efektif dan Efisien. Jakarta: Grasindo.

Soemarsono, S. dan H. Mansyur. (2002). Pendidikan Kewarganegaraan. Gramedia Pustaka Utama: Jakarta

Soekanto, S. (2003). Sosiologi Suatu Pengantar. Jakarta: PT Raja Grafindo Persada.

Spiro,PJ. (2013). "The (Dwindling) Rights and Obligations of Citizenship". William \& Mary Bill of Rights Journal. Vol.21, artikel 6, 2013. pp.25-27. 
Sudijono, A. (2009). Pengantar Evaluasi Pendidikan. Jakarta: Rajawali Pers.

Sugiyono. (2011). Metode Penelitian Kuantitatif Kualitatif dan $R \& D$. Bandung: Alfabeta, CV

Suprijono, A. (2011).Cooperative Learning. Yogyakarta: Pustaka Pelajar.

Tri Hastuti, R dan Saman, A. (2007). Mengembangkan Kecerdasan Emosional Anak. Jurnal Pendidikan Dasar Vol.8, No.1, 2007.

Trianto. (2010). Mendesain Model Pembelajaran InovatifProgresif. Surabaya: Kencana Prenada media Group.

Tilaar, HAR. (2001). Manajemen Pendidikan Nasional. Bandung: PT Remaja Rosda Karya.

Wena, M. 2009. Strategi Pembelajaran Inovatif Kontemporer. Jakarta: PT. Bumi Aksara.

Widodo. (1998). Pendidikan Pancasila dan Filsafat Pancasila. Malang: Universitas Wisnuwardana

Winaputra, Udin S. dkk. (2007). Materi dan Pembelajaran $P K n \quad S D$. Jakarta: Universitas Terbuka Depdiknas.

Winkle. (2004). Psikologi Pengajaran. Yogyakarta: Media Abadi. 